\title{
Sistemas mediáticos en democracias no consolidadas: el caso de México
}

\author{
Media Systems in Unconsolidated Democracies: the case of Mexico
}

\author{
Dr. Manuel Alejandro Guerrero \\ Universidad Iberoamericana México. \\ alejandro.guerrero@ibero.mx \\ Recepción: 5/11/2020 Revisión: 9/11/2020 \\ Aceptación: 17/12/2020 Publicación: 27/12/2020
}

\begin{abstract}
Resumen
En un régimen en transición los medios, como otros actores de peso, tienen la posibilidad de optar, dentro de ciertos límites estructurales, por determinado tipo de comportamientos en los diferentes momentos de incertidumbre. En México, durante la liberalización y la primera alternancia (2000-2018), una buena parte de los medios informativos convencionales optó por mantener intercambios convenientes con los actores políticos en lugar de presionar por la consolidación democrática mediante una transformación más profesional del quehacer informativo. Resultado: alta diversidad de medios con independencia supeditada a los intereses económicos y políticos de dueños y editores con fuertes distorsiones de las funciones informativas y de vigilancia del periodismo en general. No obstante, las cosas no han mejorado a lo largo de la segunda alternancia (2018- ), pues en la democracia mexicana, que sigue careciendo de mecanismos efectivos de responsabilidad, el mayor riesgo a la independencia informativa proviene tanto del asedio gubernamental, como de un entorno mediático en el que, con notables excepciones, buena parte de los medios convencionales ha mantenido las mismas prácticas del quehacer informativo, aunque ahora centrado en exhibir al gobierno más que en analizar e informar a la sociedad.
\end{abstract}

\begin{abstract}
In a transitional regime, the media like many other important actors have the possibility to make decisions regarding their behavior, within certain structural limits. In Mexico, during the liberalization process and the first governmental alternation (2000-2018), most mainstream media chose to maintain clientelistic exchanges with political actors instead of pressing for democratic consolidation through a more professional transformation of their informational practice. The outcome: high diversity of media with independence subject to economic and political interests of owners and publishers, that strongly distorted the reporting and surveillance functions of journalism in general. However, things have not improved throughout the second governmental alternation (2018-), since in Mexican democracy, which still lacks effective accountability mechanisms, the greatest risk to information independence comes from both the government siege and a media environment in which, with notable exceptions, many mainstream media have kept the same practices of reporting, although now focused on exhibiting the government rather than analyzing and informing society.
\end{abstract}

Palabras clave: Regímenes en transición; Sistemas mediáticos; Democracia no consolidada; Diversidad e independencia mediática; Prácticas informativas; Medios y democratización.

Keywords: Transitional regimes; Media systems; Unconsolidated democracy; Media diversity and independence; Information practices; Media and democratization. 


\section{Introducción: medios en regímenes transicionales}

La mayoría de la literatura sobre transiciones políticas sea en su variante "desde regímenes autoritarios" o "hacia la democracia", ha descuidado el análisis sobre el papel de los medios de comunicación y las redes sociodigitales, al considerar como variables dependientes de la política, la apertura y el pluralismo mediático. Una excepción notable es la obra de Katrin Voltmer, The Media in Transitional Democracies (2013), en donde propone tres aspectos: 1) los medios de comunicación son actores con ciertos rangos de acción durante las transiciones; 2) los procesos de transición no implican necesariamente la consolidación de un ecosistema mediático democrático; y 3) la diversidad y la independencia son condiciones básicas para entender el papel de los medios en un régimen político. La limitación de Voltmer es que, con todo, no logra establecer categorías ni rangos que ayuden a clasificar ni a entender mejor el tipo de sistemas mediáticos que podrían relacionarse con determinadas etapas de los procesos de transición de los regímenes políticos.

Por su parte, la literatura sobre sistemas mediáticos también ha descuidado el debate sobre los tipos de regímenes políticos más allá de los modelos ya establecidos -democracia, autoritarismo, totalitarismo-lo que da como resultado concepciones estáticas predecibles de lo mediático: "libre" con la democracia y "controlado" en distinto grado en los otros dos.' Una excepción es el trabajo de Vaca (2017), para quien los conceptos "democracia" y "autoritarismo" ya no necesariamente reflejan las principales transformaciones de los sistemas mediáticos. Sin embargo, si bien es viable suponer que, en general, lo político delinea los contornos de lo mediático, perfilando tendencias hacia determinadas formas de sistemas, de ningún modo se trata de ámbitos estáticos, especialmente al hablar de los regímenes transicionales.

Durante las transiciones surgen coyunturas que posibilitan la acción ("agencia") para diversos actores -los medios claramente incluidos (Voltmer 2013) - que pueden ser aprovechados, o no, para replantear no sólo la relación con lo político, sino con sus públicos, con su entendimiento de lo informativo, lo profesional y con la independencia periodística. En ciertos momentos y circunstancias, la estructura mediática tiene la posibilidad de incidir en el camino hacia la consolidación democrática, o, por el contrario, de buscar acomodos convenientes con los grupos en el poder.

Este capítulo forma parte de un proyecto de investigación más amplio sobre sistemas mediáticos en regímenes en transición, aunque aquí sólo se analiza la forma en que se estructura el sistema mediático en el caso de México a partir de las dos condiciones que ya menciona Voltmer (2013), diversidad e independencia, en un contexto de régimen de democracia no consolidada. A diferencia de los otros dos grandes tipos de regímenes transicionales -aquellos que transitan de una forma de autoritarismo a otra y aquellos que se estancan en una fase híbrida con instituciones nominalmente democráticas, pero no funcionales-los regímenes democráticos no consolidados presentan mayores oportunidades para que los medios puedan actuar a favor de la consolidación o bien acomodarse con las (nuevas y no tan nuevas) clases políticas, privilegiando lo que en otros espacios hemos definido como "modelo liberal capturado" (Guerrero 2014). No obstante, lejos de implicar una aceptación determinista, cualquier resultado deriva de un escenario que define el tipo de modelo transicional (estructura) donde los actores mediáticos optan por determinadas estrategias (agencia) sobre otras.

El capítulo inicia clasificando a la democracia como un tipo de régimen político con base en el análisis de sus componentes principales -el acceso y el ejercicio del poder-, así como del lugar de los medios a partir de las condiciones referidas de diversidad e independencia, y de cómo éstas afectan sus funciones como informadores, arenas de debate y vigilancia (watchdog). Desde este marco se analiza el caso de México en los apartados subsecuentes. Primero, mediante una breve descripción tanto de las condiciones que gestaron el modelo de relación clásico durante el régimen priista, como del modo en que los medios convencionales optaron por la apertura en 
distintos momentos durante el largo del proceso de liberalización política. Segundo, mediante el análisis de los reacomodos convenientes que los medios buscaron con las nuevas élites políticas, a partir de lo que aquí se llama la primera alternancia (2000-2018), al aprovechar las dos condiciones mencionadas (diversidad e independencia) para negociar intercambios, en lugar de profesionalizar su quehacer informativo y presionar por la consolidación. ii Tercero, a través de discutir los cambios impulsados por el régimen de la segunda alternancia (2018 - ) en relación con los medios: la redefinición de la publicidad oficial, la pretensión de circundar a los medios mediante conferencias diarias y redes sociodigitales, y la confrontación sistemática con muchos de los principales medios convencionales. El segundo y tercer apartados presentan asimismo observaciones sobre el rol tanto de las redes sociodigitales, como de las principales formas del periodismo en el contexto de las dos alternancias. La conclusión es que, a pesar de la diversidad mediática alcanzada, la independencia sigue estando bajo asedio, lo cual afecta, sobre todo, la posibilidad de fortalecer el papel de vigilancia informativa tanto por presiones gubernamentales, como por intereses de las organizaciones mediáticas mismas, lo cual ocurre en regímenes políticos que no han logrado consolidar un ejercicio del poder responsable.

\section{Regímenes políticos, medios y democracia}

Prácticamente desde la segunda Guerra Mundial, la ciencia política -sobre todo la estadounidense - ha buscado definir a los regímenes democráticos a partir de ciertas características mínimas que puedan distinguirlos de otras formas de gobierno (Møller y Skanning, 2010). La cuestión es, ¿qué características deben considerarse esenciales a una democracia? En un trabajo que se volvió un clásico del tema, Robert Dahl (1971) señalaba ocho atributos mínimos que toda democracia real o "poliarquía" debía tener. iii Sin duda, los criterios de Dahl han sido muy útiles para definir procedimentalmente a la democracia moderna, entendida fundamentalmente con base en criterios electorales y de participación. Desde entonces ha surgido un buen número de proyectos para medir la democracia, desde los índices de Freedom House, los del Economist Intelligence Unit, el Democracy Barometer o el proyecto Varieties of Democracy, entre otros.

Sin embargo, para inicios del siglo XXI algunas de las democracias inauguradas desde la "tercera ola", no sólo han tenido retrocesos, sino que han permanecido en zonas grises complejas en donde parecen haberse acomodado, al grado de que, para algunos (Carothers 2002; Hobson 2003), esto representaba el "fin del paradigma de la transición". A pesar del respeto al voto y la participación, de contar con sistemas de partidos competitivos y alternancia en el poder, algunas de estas democracias no han logrado consolidar mecanismos de responsabilidad política, de rendición de cuentas, de transparencia, ni tampoco estados de derecho efectivos. Hay autores que incluso han llegado a definir a algunos de estos regímenes, en casos extremos, como "poliarquías sin Estado de derecho" (O’Donnell 1999), "autoritarismos competitivos" (Lewitsky y Way 2002) o "democracias iliberales" (Smith y Ziegler 2008).

Al mismo tiempo, otros autores comenzaron a hablar de "calidad de la democracia" (Diamond y Morlino, 2004), enfocándose en características complementarias a lo electoral. Para Diamond y Morlino, hay nuevamente ocho dimensiones en las que las democracias varían en calidad: libertades, estado de derecho, igualdad, participación, responsividad, competencia, y rendición de cuentas vertical y horizontal. Estas dimensiones, indican, tienden a moverse en conjunto, ya sea hacia la consolidación o hacia la regesión. A partir de aquí, mucho se ha debatido acerca de qué aspectos sumar o restar a los criterios mínimos para definir un régimen como democrático, añadiendo a la existencia de elecciones competitivas, libertades civiles adicionales (Collier y Levitsky 1997), derechos de asociación (Norris 2012), estado de derecho (Møller y Skaaning 2012), responsividad (Bühlmann et al. 2008), resultados sociales (Campbell et al. 2015), hasta roles más activos de la sociedad civil (O'Donnell 1998) y la necesidad de incluir la perspectiva de la ciudadanía sobre el gobierno (Pickel, Breustedt y Smolka 2016). iv 
El problema de fondo no es el número de criterios, pues la lista puede ser tan corta o larga como se desee, sino perder de vista la necesidad de conceptualizar dos dimensiones clave de todo tipo de régimen político: el acceso y el ejercicio del poder. El politólogo argentino Sebastián Mazzuca (2010) ha señalado que las formas de acceder al poder y las formas de ejercicio del poder son atributos básicos de toda definición de régimen político. Esta distinción resulta útil para analizar la democratización como una serie de procesos que se localizan en el ámbito del régimen político. Sin embargo, al contrario de Mazzuca, quien considera que la democracia es sólo una forma de acceso al poder (es decir, restringida a lo electoral), ya en otros trabajos se ha sostenido que la democracia debe considerarse como un tipo de régimen político, y por tanto, lo que hay que estudiar son los elementos que componen tanto sus formas particulares y específicas de acceso al poder, como las de su ejercicio."

El acceso democrático al poder se refiere a las formas en las que diferentes individuos y grupos compiten por alcanzarlo a partir de los mecanismos y reglas, formales e informales, que especifican quiénes pueden participar y quiénes no en los asuntos públicos. En un régimen democrático, estas reglas y estos mecanismos tienen que ver con una competencia abierta y relativamente equilibrada, con la participación popular y con condiciones que aseguran la rendición de cuentas y la alternancia en el poder en función del voto. En buena medida, los atributos de Dahl definen estas formas de acceso al poder: libres, competitivas, equitativas y participativas. Se puede sintetizar entonces que en un régimen democrático las formas de acceso se esperaría que fueran abiertas.

Por su parte, las formas de ejercicio del poder en una democracia se definen por ser limitadas y equilibradas. Limitadas en el sentido de las formas en que el poder del régimen se extiende en la sociedad (Dunn 1999). Aquí se habla, por ejemplo, de criterios relativos a la existencia efectiva de un estado liberal de derecho que limita el poder público frente a los derechos y libertades de individuos y grupos, pero también de criterios de responsividad y de cierto tipo de rendición de cuentas y transparencia. El equilibrio, en cambio, tiene que ver con las formas en que el poder se distribuye y se comparte entre diferentes órdenes e instituciones (O'Donnell 1998). Se hablaría de criterios relativos a pesos y contrapesos y, nuevamente, a ciertas formas de rendición de cuentas y de transparencia. Se puede sintetizar entonces que en un régimen democrático las formas de ejercer el poder se esperaría que fueran responsables.

En suma, todo tipo de régimen político se compone de una dimensión relativa al acceso al poder y otra a su ejercicio. La democracia, al ser un tipo de régimen, se compone de formas específicas de estas dos dimensiones -el acceso al poder mediante formas libres, competitivas, equitativas y participativas (acceso abierto), y el ejercicio limitado y equilibrado del poder (ejercicio responsable)-, y, desde luego, se pueden discutir cuáles podrían ser sus criterios específicos y, otra vez, la lista puede acortarse o alargarse cuanto se desee.

A partir de aquí, es posible plantear el lugar de los medios informativos y del periodismo en un régimen democrático con base en dos aspectos clave, las condiciones y las funciones. Voltmer (2013) señala que el grado de diversidad e independencia favorecen las posibilidades de los medios informativos para servir de vigilantes (watchdogs) y reportar los abusos de poder. Para esta autora, la diversidad tiene que ver con la variedad de medios disponible (diversidad externa) y de tecnologías de información disponibles, así como también con la heterogeneidad de puntos de vista que se incluyen en cada medio (diversidad interna). Siguiendo a Voltmer, la independencia, a su vez, se relaciona con aspectos como el grado influencia gubernamental, la disponibilidad de fuentes, la concentración de la propiedad, y la dependencia financiera de los medios. Pero también con el grado de autonomía de los periodistas y editores frente a los dueños. Así, estas dos condiciones, no sólo favorecen la función de watchdog, como dice Voltmer, sino también otras tres: la capacidad informativa, el servir de arena de debates para los principales 
temas de la agenda y las posibilidades efectivas de ejercer un compromiso profesional por parte de los periodistas.

En un régimen democrático, los medios informativos y el periodismo son fundamentales para mantener formas abiertas de acceso al poder, al reportar sobre los procesos electorales, los actores en competencia, los temas más relevantes, y en el camino, fomentar la participación, las libertades de expresión y el empoderamiento cívico. Al mismo tiempo, los medios y el periodismo también son esenciales para fomentar la responsabilidad política en el ejercicio del poder al buscar hacer efectivas la responsividad, la rendición de cuentas y la transparencia. La capacidad de los medios informativos y del periodismo para cumplir con estas expectativas depende, en parte, del grado de desarrollo de las dos condiciones estructurales mencionadas (diversidad e independencia), pero también de la agencia de los propios medios y periodistas para aspirar al cumplimiento efectivo de las cuatro funciones referidas (informar, servir como espacio de debate, compromiso profesional y watchdog). En términos ideales, entonces, bajo estas condiciones y capacidades, los medios informativos pueden convertirse en aliados ciudadanos en favor de una arena pública democrática (Keane, 2013).

\section{El caso de México: transición inconclusa y apertura mediática}

En 2004, Baracca publicó un artículo en el Third World Quarterly donde definía a México como una democracia consolidada, al entender la consolidación como la ausencia de condiciones de inestabilidad y de quiebra evidentes. Baracca enfatizaba que en el país no existían condiciones de rechazo, por ejemplo, a los resultados electorales y otros aspectos procedimentales. Si bien, haber pasado cierto umbral que permita suponer como poco probables condiciones abiertas de regresión y de quiebra democrática es sin duda un gran avance, considerar esta situación como "consolidación" resulta poco adecuado tan sólo con base en aspectos procedimentales de la democracia sin considerar otros aspectos sustantivos del ejercicio del poder, como la rendición de cuentas.

Este apartado plantea dos análisis complementarios. Primero, define a la mexicana como una democracia no consolidada (por tanto, atrapado en una transición inconclusa) a partir de la revisión de un proceso largo de liberalización política que le ha permitido establecer formas de acceso al poder cada vez más abiertas (libres, competitivas, equitativas y participativas), al tiempo que mantiene formas de ejercer el poder poco responsables (distorsiones en la transparencia, baja responsividad, presiones para reducir los pesos y contrapesos, y baja rendición de cuentas). En segundo lugar, se muestra cómo esta situación, si bien ha favorecido un panorama mediático relativamente diverso, no ha logrado consolidar una tendencia hacia mayor independencia mediática debido, sobre todo, a que gran parte de los medios convencionales ha buscado acomodar sus intereses más que modificar las prácticas del quehacer informativo (watchdog, entre otras) a favor de un ejercicio del poder más responsable.

\subsection{Los límites del cambio político: alternancias electorales sin consolidación democrática}

Desde fines del siglo XX, las formas de acceder al poder político en México se han vuelto aparentemente más plurales y abiertas: hay una arena electoral cada vez más competitiva y mayor reconocimiento a la participación política, sobre todo mediante el voto. Ello resulta de un largo proceso de cambio político en el que régimen y oposición fijaron desde el inicio su campo de disputa en lo electoral. Este proceso inició como una liberalización política (O'Donnell y Schmitter 1986 ) en un régimen que deseaba mantenerse en el poder, al tiempo que respondía a nuevas demandas a través de abrir nuevos espacios de participación, sobre todo, después de 1968, hacia sectores que crecieron por fuera de los canales corporativos, como las clases medias. ${ }^{\text {vi }}$ Este fue el 
objetivo de la Reforma política de 1977: ampliar la participación electoral, terreno en que la oposición concentró los esfuerzos de sus reclamos de apertura. ${ }^{\text {vii }}$

La crisis del modelo de desarrollo desatada a inicios de los 80 s marcaría el escenario para las siguientes reformas y contrarreformas políticas en medio de un creciente "voto de castigo" al régimen y mayor presencia electoral de la oposición (Loaeza, 1987). La apertura definitiva de las formas de acceso al poder quedaría establecida a partir de la Reforma de 1996 que, entre otras cosas, inauguraba la posibilidad de independencia del Instituto Federal Electoral, así como también garantizaba una enorme cantidad de recursos a los partidos políticos para la competencia electoral y sus campañas políticas.

Si bien, la primera experiencia de alternancia en el poder había ocurrido a nivel estatal en 1989, en Baja California, y posteriormente con la derrota del PRI en las primeras elecciones a la jefatura del gobierno del entonces Distrito Federal, la victoria de Vicente Fox en las elecciones presidenciales de 2000 trajo consigo la posibilidad de acometer los cambios necesarios para la consolidación democrática. No obstante, en lugar de culminar un proceso de transición democrática, el cambio inauguró nada más un periodo que llamo aquí la primera alternancia, 2000-2018. viii Si en lo electoral, México acababa de pasar su prueba de ácido, y el país ya se podía contar entre las democracias electorales, ahora se hacían urgentes reformas que se orientaran a corrigir el abuso de poder, la falta de responsividad, rendición de cuentas y transparencia. ¿Qué se intentó en estos 18 años?

El gobierno del presidente Fox anunció, primero, la Ley Federal de Transparencia y Acceso a la Información en 2002 -y la creación, un año después del Instituto Federal de Transparencia (IFAI)-, que establecía la publicidad de la información en poder del gobierno y abrió el camino a una serie de reformas posteriores que concluirían con una amplia reforma constitucional al artículo 6은 en 2006. Con todo, el peso de lealtades y cuotas partidistas en la nominación de los comisionados -tanto los nacionales como los estatales-ha impedido transitar de la transparencia a una auténtica rendición de cuentas en muchos temas cruciales (Dussauge 2010). En 2003 también se aprobó la Ley del Servicio Profesional de Carrera en la Administración Pública Federal que, en principio presentaba la oportunidad de reducir el control político de los puestos, de fomentar la lealtad institucional, y de combatir una de las formas más añejas de corrupción del aparato del Estado mexicano (Merino 1999). Sin embargo, muy pronto se hallaron formas de mantener viejas prácticas, entre otras, mediante la creación de un gran número de plazas de confianza que no pasaban por los mecanismos de concurso establecidos en ley. La recién creada Secretaría de la Función Pública también enfrentaba dificultades estructurales en su operación: básicamente al carecer de independencia jurídica y política frente al Ejecutivo (Pardo, 2009; Dussauge, 2010).

Por su parte, los gobiernos de los presidentes Calderón y Peña Nieto tampoco lograron grandes avances en reformar el ejercicio del poder. El primero dio inicio a una política de combate abierto a los grupos del narcotráfico con un costo tan alto en vidas humanas, desplazamiento, desapariciones y abusos a los derechos humanos, que resultaba un contrasentido hablar de formas limitadas y equilibradas en el ejercicio del poder. Con todo, en 2011 se aprobó una reforma muy importante en materia de derechos humanos que, si bien en el papel ponía a México a la vanguardia (García Castillo, 2015), al final de cuentas no pudo cerrar el paso a abusos y violaciones, además de que parecía faltar voluntad política para que organismos como las fiscalías y defensorías pudieran operar con mayor efectividad y eficacia y reducir una impunidad. ${ }^{\text {ix }}$

El gobierno del Presidente Peña Nieto mantuvo la vigencia de la política de guerra de su antecesor -aunque ya no se le denominaba así en los medios-con un número de víctimas mayor, sonados casos de violaciones a derechos humanos (Tlatlaya, Ayotzinapa), y saldos negativos en materia de rendición de cuentas y de transparencia. ${ }^{\times}$Todo ello, a pesar de una serie de reformas tendientes a la creación del Sistema Nacional Anticorrupción, que tampoco pudo 
comenzar a operar. Así, para 2018 muy poco se había logrado en términos de reformas efectivas hacia un ejercio del poder más responsable.

En gran parte, el descontento acumulado ayuda a explicar la victoria electoral de Andrés Manuel López Obrador, quien luego de dos intentos fallidos, gana la presidencia con poco más de 30 millones de votos (63.42\% de participación) y también, junto con los partidos de su coalición, la mayoría en las dos cámaras. A lo largo de su campaña, el candidato López Obrador prometió reformas de fondo en el ejercicio del poder para poner fin a la violencia y a la corrupción, así como para operar el gobierno y para lograr un desarrollo incluyente que mirara, fundamentalmente, por los grupos más vulnerables. Sin embargo, a dos años del inicio de su gobierno habría más evidencia para suponer un distanciamiento de ciertas prácticas anteriores en el quehacer administrativo que una ruta de consolidación institucional para lograr un ejercicio del poder másresponsable. Hasta ahora, este periodo ha resultado ser una segunda alternancia.

Por lo pronto, se siguen registrando saldos negativos altos en varios frentes, como la contención de la violencia ${ }^{\mathrm{xi}}$ y el combate a la corrupción se basa más en procesos judiciales contra personajes específicos que en fortalecer el andamiaje institucional de prevención y vigilancia. Nada se dice ya del Sistema Nacional Anti-corrupción. En cuanto al fortalecimiento del estado de derecho, la impartición de justicia y el combate a la corrupción, el Índice de Estado de Derecho realizado por el World Justice Project -elaborado a partir de diferentes mediciones y ponderaciones que incluyen ONGs, tomadores de decisiones, académicos y expertos- sitúa a México en el lugar 104 de 128 países con pocos resultados concretos en los ocho factores que contempla: límites al poder gubernamental, corrupción, justicia civil y penal, derechos fundamentales, orden y seguridad, y cumplimiento regulatorio. ${ }^{\text {xil }}$ Por lo que toca a la gestión gubernamental, uno de los mayores pilares ha sido el recortes indiscriminado y el el ahorro, que de acuerdo a estudios se han traducido sobre todo en un desmantelamiento de la Administración Pública Federal y una seria disminución de su capacidad operativa (Villalpando y Morales, 2020). En suma, las transformaciones que ha impulsado el gobierno del Presidente López Obrador, si bien, marcan un rumbo distinto al del modelo de desarrollo anterior, no parecen estar orientadas ni a un fortalecimiento institucional, ni tampoco a establecer límites, equilibrios y contrapesos en el ejercicio del poder. Por tanto, es posible afirmar que ninguna de las dos alternancias ha sido capaz de proponer reformas y cambios institucionales eficaces y efectivos para consolidar la segunda dimensión de un régimen democrático, la del ejercicio del poder más responsable. En México se mantiene una democracia no consolidada que, si bien cumple en cuanto a las formas democráticas de acceso al poder, queda mucho a deber en cuanto a su ejercicio.

\subsection{La apertura a la diversidad en los medios: de la censura ambiental a los arreglos convenientes}

Entre las décadas de 1930 y 1970, el resultado de la relación entre el régimen político y los medios de comunicación podría definirse, en palabras de Granados Chapa (1981), como una "censura ambiental". Con ello se hacía referencia a,

Un contexto en el que se desarrolló una complicidad entre los medios y el régimen que permitió a los primeros gozar de beneficios para consolidarse como negocios rentables a cambio de mantener un espacio público de debate limitado y un apoyo general al régimen. A ello habría que añadir la inexistencia de una condición necesaria para una transmisión de contenidos más abiertos y críticos: una oposición débil y mal organizada, así como escasas vías institucionales para manifestar la participación política de oposición. De este modo, la conveniencia, los intercambios y la debilidad de alternativas políticas definieron la relación entre los medios y el régimen por décadas (Guerrero 2010: 235). 
Entre los principales elementos favorables a esta forma de relación se podían contar: las estrechas relaciones entre dueños y editores con grupos políticos, la centralización de la información (no había mecanismos de transparencia), el control relativo sobre la producción de papel para periódicos y revistas, el control sobre la distribución de periódicos a cargo de un sindicato afiliado al partido oficial, la discrecionalidad con la que se asignaban frecuencias y concesiones de radiodifusión, el peso de la publicidad oficial y las diversas compensaciones salariales que desde las nóminas gubernamentales se pagaban a reporteros y periodistas (lbidem).

Esta situación cambió, primero en la prensa escrita, luego en la radio y finalmente en la televisión. Prácticamente a la par del inicio del proceso de liberalización política en la segunda mitad de los años 70, una nueva generación de medios impresos comenzó a desafiar al régimen a partir de la crítica a los excesos del poder (Proceso, UnoMásUno y poco después, La Jornada, El Financiero). En la radio, ya entrados los años 80 , con la crisis económica en auge, como estrategia de supervivencia, las estaciones comenzaron a apostar por espacios informativos más largos y, por vez primera, con voces críticas. ${ }^{\text {xiii }} \mathrm{Y}$, por lo que toca a la televisión, no fue sino hasta que se conjugó un relevo generacional, sobre todo en Televisa, con una Reforma política en 1996 -que garantizó a los partidos políticos la mayor cantidad de recursos en su historia, sobre todo, para utilizarse en las campañas políticas- que las dos principales cadenas terminaron de abrir sus espacios a voces de la oposición. ${ }^{\text {xiv }}$ De este modo, para fines del siglo XX, se perfilaban las condiciones de una apertura informativa que reflejaba la diversidad mediática y la incipiente independencia que comenzaban a verse tanto en ejercicios críticos al poder en varios espacios de la prensa escrita, como en la incorporación de voces de las oposiciones que ya se podían escuchar y ver en los noticieros.

Con todo, la llegada de nuevos partidos políticos al poder por la vía electoral, lejos de ser aprovechada para que la diversidad mediática fortaleciera su independencia y profesionalizara su quehacer informativo, sirvió en cambio para que la mayor parte de las organizaciones informativas optara por ajustar los esquemas de relación desarrollados con el viejo régimen a nuevas condiciones de intercambio más convenientes con las élites políticas recién llegadas. Al respecto es muy importante tomar en cuenta que la apertura en las formas de acceso al poder en México en la segunda mitad de los años 90 ocurría en un contexto global en donde la comunicación política y el papel de los medios en los procesos electorales se estaban convirtiendo en piezas fundamentales para las campañas, siguiendo modelos estadounidenses (Blumler y Gurevitch 2001; Negrine y Papathanassopoulos 2005). Así, la competencia electoral en México se fortalecía en momentos en que los principales campos de batalla -que nunca los únicos-eran los espacios mediáticos, sobre todo las pantallas televisivas (Plesser 2002). Al considerar la gran cantidad de recursos que el entonces Instituto Federal Electoral garantizaba a las contiendas, la apertura electoral significaba para muchos medios convencionales, más que una oportunidad de ejercer su función informativa de forma veraz y oportuna, una ocasión de hacer negocios con base en apuestas más o menos veladas a favor o en contra de los distintos partidos y candidaturas en disputa. ${ }^{\mathrm{xv}}$ Desde luego, esto no significa ni que todos los medios ni todos los periodistas actuaran con esta lógica, pero sí era la tendencia dominante en el panorama mediático general del país.

La independencia mediática, entonces, no sólo era moneda de cambio durante los procesos electorales, sino también a la hora de convertir en gobierno a las alternativas vencedoras del voto. En este sentido, ante mercados publicitarios comerciales, tanto nacionales como locales, que no necesariamente lograban financiar por sí solos una diversidad de medios de comunicación, la alternativa de buscar la publicidad gubernamental no sólo suponía una promesa de supervivencia, sino una posible alianza táctica con grupos políticos determinados. ${ }^{\text {xvi }}$ Después del año 2000 , ya no se trataba de un régimen piramidal que se ordenaba a partir del plano federal, sino de 32 alternativas gubernamentales y algunas otras municipales lo suficientemente solventes como para ejercer importantes recursos en comunicación social. Durante los sexenios de la primera 
alternancia (2000-2018) no hubo entonces necesidad en los medios de transformar las rutinas para profesionalizar el quehacer periodístico, sino de preservar los negocios al mantener los apoyos, en general, al estatus quo, mediante viejas prácticas informativas.

Así, en conjunto, la información sobre la vida pública que presentaban los principales medios informativos seguía basándose en las declaraciones de los actores políticos, en notas con escaso contexto por sobre cualquier otro género periodístico, en pocas fuentes, casi sin contraste, y en información sin seguimiento. En pocas palabras, los principales medios informativos seguían practicando -como en los viejos tiempos-el mismo tipo de rutinas informativas orientadas a promover al cliente, más que a informar, fomentar el debate y vigilar. Un episodio, en particular, ayuda a ilustrar este panorama general de intercambios entre medios y política.

En mayo de 2012, luego de cinco meses de campaña y a la cabeza de todas las encuestas de preferencia electoral, el candidato de la alianza "Compromiso por México" (PRI y Partido Verde), Enrique Peña Nieto, acudió a la Universidad Iberoamericana en donde tuvo un desencuentro con los estudiantes, quienes le reclamaron por la violencia ejercida por parte de las fuerzas de seguridad del Estado de México (de donde había sido apenas gobernador) contra pobladores y manifestantes en el poblado de San Salvador Atenco en 2006. El candidato Peña Nieto tuvo que ser escoltado fuera de la universidad entre gritos y abucheos de la comunidad estudiantil. Esa noche, el principal informativo de Televisa, El Noticiero con Joaquín López Dóriga presentó el suceso del mismo modo en que algunos medios impresos lo harían al día siguiente, inculpando a supuestos grupos de infiltrados cuyo objetivo era boicotear el evento (Redacción AN, 2012). Esta desinformación desató la ira de los estudiantes quienes se organizaron mediante redes sociodigitales para exponer la manipulación informativa, lo cual gestó los movimientos @Másde131 en la Iberoamericana y \#YoSoy132 entre muchas más personas en otras instituciones educativas y sectores sociales. Estos movimientos, encabezados por estudiantes, organizaron manifestaciones masivas y, con apoyo logístico de Google, un debate adicional presidencial a los del Instituto Federal Electoral, a través de plataformas digitales -debate al que no acudió el candidato Peña Nieto. El reclamo original contra la manipulación informativa se mantuvo como uno de los principales reclamos del movimiento y tuvo un doble impacto.

Primero, ante la presión, el candidato Peña Nieto se comprometió a proponer, en caso de ganar, una nueva ley de medios que contemplara criterios y limitaciones sobre los topes de gasto en comunicación social y la manera en que se debían repartir los recursos. Esto lo cumplió parcialmente hasta el final de su sexenio, en mayo 2018, al aprobar una Ley General de Comunicación Social, que reglamentaba lo establecido en el artículo 134 constitucional y que, sin embargo, dejaba varios cabos sueltos, pues no establecía objetivos, ni criterios de asignación de recursos (DOF 11/05/2018). Tampoco fijaba topes de gasto, ni mecanismos de fiscalización claros; carecía de mecanismos de sanción contra la propaganda personalizada y centralizaba decisiones y responsabilidades de planeación en la Secretaría de Gobernación.

Segundo, a partir de entonces las redes sociodigitales se volverían cada vez más relevantes en el debate de la agenda pública. A través de ellas, sectores y grupos comenzaron a manifestar su inconformidad al gobierno en diferentes momentos y por distintos motivos: justicia por el número creciente de víctimas de las violencias, reclamos por la impunidad frente a la corrupción rampante, denuncia por los recurrentes abusos contra periodistas, entre otros. Es importante notar que durante la gestión del presidente Peña Nieto, a pesar de los supuestos "bots" que mecánicamente replicaban información favorable a su administración, la discusión general en las redes estaba marcada por un profundo espíritu crítico frente al estatus quo, diferente de lo que se presentaba cotidianamente en los principales medios de comunicación convencionales.

De este modo, a lo largo de los tres sexenios de la primera alternancia (2000-2018), el panorama mediático se caracterizó por una diversidad creciente de medios y plataformas, al tiempo que muchos de los principales informativos convencionales optaron por mantener, con actores 
políticos de todos los partidos y con distintos órdenes de gobierno, relaciones clientelares de intercambio de apoyos económicos (desde la publicidad gubernamental hasta las compensaciones salariales) por apoyo político (desde no reportar sobre determinados temas hasta destacar las versiones oficiales sobre otros más). Un panorama mediático definido por una aceptable diversidad, pero con una independencia condicionada fundamentalmente por intereses extramediáticos, económicos y políticos, aunque también, en ciertas regiones del país, por las diferentes formas de violencia contra periodistas.

A partir de estas dos condiciones generales del panorama mediático en México -diversidad con independencia condicionada-, no sorprende que, en la mayor parte de los medios convencionales, la defensa interesada del estatus quo terminara por distorsionar las funciones informativas, de arena de debates y, sobre todo y muy especialmente, la de vigilancia, manteniendo lo que hemos llamado ya un "periodismo colaborador" (Guerrero 2019). Sin embargo, a lo largo de este mismo periodo, gracias en gran medida a la revolución tecnológica, comenzó también a ser más visible otro tipo de periodismo alternativo, más comprometido y profesional a contrapelo de las tendencias dominantes que también hemos denominado "periodismo responsivo" (Ibidem). Un periodismo que si bien, siempre ha existido en México, la revolución tecnológica le otorgó mayor presencia, alcance y, sobre todo, autonomía frente a las organizaciones y plataformas mediáticas convencionales. Sitios como Animal Político, SinEmbargo, La Silla Rota, Aristegui Noticias, Reporte Índigo, entre otros, fueron ganando prestigio y lectores tanto por los tipos de historias que publicaban, como por los ángulos desde los que lo hacían. $Y$, junto a ellos, también en este periodo aparecieron grupos y colectivos de periodistas de distintos medios que comenzaron a colaborar en investigaciones de mayor envergadura al compartir una misma visión ética y profesional, al tratar temas que usualmente carecen de espacio en los medios convencionales desde ángulos también novedosos. Para concluir, habría que señalar que también en este periodo, sobre todo a partir de 2006, el periodismo que se practica en ciertas regiones y en ciudades pequeñas y medianas ha estado bajo el ataque constante de grupos que recurren a la violencia como mecanismo de control. Se trata de un "periodismo acosado" (Ibidem) debido a la fragilidad de condiciones en las que se desempeña y que, por un lado, tienen que ver con el contexto institucional y de mercado regional y local y, por el otro, con la falta de garantías básicas para poder desempeñarse de forma profesional y autónoma.

\section{Régimen político y medios en la segunda alternancia: de la conveniencia al enfrentamiento}

La llegada al poder del presidente Andrés Manuel López Obrador ha supuesto un cambio importante en la relación del gobierno con los medios de comunicación. Este cambio se podría centrar en tres aspectos:

- Un intento por romper el viejo esquema de relación entre medios y régimen a partir del uso de la publicidad oficial.

- Una política de comunicación centralizada en conferencias diarias y basada en el empleo de redes sociodigitales.

- Un enfrentamiento verbal sistemático con medios de comunicación y con periodistas específicos.

En relación con el primero, no puede perderse de vista que, con base en datos de FUNDAR y Article XIX, el gobierno del presidente Peña Nieto gastó 61 mil 659 millones de pesos en 
publicidad oficial, lo que significó un gasto $89 \%$ superior a lo presupuestado, de lo cual $52 \%$ se concentró tan sólo en diez organizaciones mediáticas (FUNDAR, 2019). De acuerdo con el Instituto Mexicano para la Competitividad (IMCO), sólo en 2018, el gasto en publicidad oficial presupuestado fue de 1 mil 160 millones de pesos, pero el ejercido terminó en 6 mil 373 millones, es decir $449 \%$ superior (Guadarrama, 2019). Este enorme gasto se explica, en gran parte, por los acuerdos clientelares referidos. Por lo que, ante el reclamo social en relación con este tema, el candidato López Obrador se comprometió en campaña a promover una nueva ley de publicidad oficial, anunciándolo como uno de sus 100 compromisos en su toma de posesión en diciembre de 2018.

En enero de 2019 se publicaron los "Lineamientos generales para el registro y autorización de los programas de comunicación social de las dependencias federales" (DOF 29/01/2019) y el 17 de abril del mismo año se anunció el "Acuerdo por el que se establece la Política de Comunicación Social del Gobierno Federal" (DOF 17/04/2019) que enfatiza una reducción de gasto de $50 \%$ en relación con lo presupuestado y en caso de llevarse a cabo una ampliación presupuestal en este rubro no se podrá rebasar de $0.1 \%$ del monto en ningún ejercicio fiscal subsecuente durante esta administración. Otras novedades de este Acuerdo limitan los contratos anuales con medios de comunicación, la concentración mayor a $25 \%$ en un solo medio de la pauta destinada a una sola campaña, la renegociación de tarifas publicitarias y, en cambio, privilegia a los medios públicos en las campañas. Quizá el aspecto más claramente dirigido a acotar el viejo modelo de relación entre los medios y el gobierno sea la serie de prohibiciones expresas para emplear la comunicación social como mecanismo de intercambio de beneficios por apoyos. El Acuerdo prohíbe:

I. Presionar, castigar, premiar, privilegiar o coaccionar a los comunicadores o a los medios de comunicación;

II. Realizar erogaciones por concepto de notas, entrevistas o imágenes con fines periodísticos;

III. Otorgar recursos públicos encubiertos que beneficien, directa o indirectamente, a los medios de comunicación;

IV. Recibir algún pago, a través de la prestación de servicios de publicidad, impresiones, inserciones y demás relativos a las actividades de comunicación social, salvo lo previsto en la Ley General de Comunicación Social, y

V. Difundir publicidad con contenidos y demás fines prohibidos por las disposiciones jurídicas aplicables.

Estas medidas, en principio, representan una ruptura histórica con un modelo de relación que, por décadas, ha fomentado la colusión entre medios y régimen. No obstante, no forman parte de un nuevo marco legal en la materia, pues se limitan al Acuerdo vigente, en todo caso, para esta administración. Adicionalmente, se anunció que se establecerían criterios transparentes y objetivos para asignar los recursos a los medios. A más de un año de la entrada en vigor del Acuerdo, si bien hay mayor transparencia a la asignación del gasto, se ha limitado su ejercicio y hay candados para evitar el uso propagandístico del gasto publicitario, el principal marco legal sigue siendo la Ley General de Comunicación Social de 2018 y no hay aún criterios definitivos contra la discrecionalidad y la desigualdad en la asignación de recursos. Este aspecto sigue siendo problemático, pues de acuerdo con el informe anual de Article XIX , Disonancia, voces en disputa (2020), si bien, ha habido efectivamente una reducción muy importante en el gasto gubernamental en publicidad oficial, durante el primer año de gobierno del Presidente López Obrador, del gasto total, --1 mil 500 millones de pesos-, un tercio se distribuyó entre tres medios (TV Azteca, \$168.5 millones; Televisa, \$160 millones; y La Jornada, \$124.3 millones). Más aún, $52 \%$ del gasto publicitario se concentró en 15 medios y el resto quedó repartido en 472 organizaciones, sin criterios claros que expliquen tal asignación. 
Así, se puede decir que si bien el gobierno del presidente López Obrador ha sentado bases importantes para fracturar la columna vertebral del modelo de relación basado en la colusión entre medios y régimen, faltaría que quedaran asentadas en ley y que se acompañaran de criterios de asignación. De lo contrario, estas medidas terminarán por ser más el resultado de un estilo particular de esta administración que un verdadero cambio de fondo. En este sentido, se podría entender, por ejemplo, que sin mayor consulta ni discusión pública, el Presidente haya decretado la devolución de una parte de los llamados tiempos fiscales a la radiodifusión en abril de 2020, para su uso comercial. ${ }^{\text {xvi }}$ La explicación que ofreció el Presidente López Obrador, si bien a todas luces insuficiente, denota otro aspecto importante de su relación con los medios: el gobierno, dijo, no necesita publicidad oficial, pues mantiene "una comunicación permanente con el pueblo" [sic].

Quizá como parte del aprendizaje que tuvo Andrés Manuel López Obrador a lo largo del tiempo y, sobre todo, del papel que comenzaron a jugar las redes sociodigitales a partir de 2012, su principal estrategia de comunicación durante los años previos a su victoria electoral de 2018 se canalizó a través de estas plataformas, al grado que en su discurso como candidato ganador del $1^{\circ}$ de julio en el Zócalo agradeció a "las benditas redes sociales" por haber contribuido a su triunfo. En gran parte, la estrategia respondía a su desconfianza en los medios informativos convencionales que, en años anteriores, pero sobre todo durante la campaña de 2006, hicieron eco a la propaganda que lo retrataba como un "peligro para México" y que posteriormente le condicionaron los espacios informativos.

Al mismo tiempo, López Obrador supo aprovechar el desprestigio de la última parte de la administración del presidente Peña Nieto y la creciente ola de indignación que generaba para canalizar de forma orgánica la conversación en las redes -que ya era muy crítica del estatus quo- hacia un anhelo de cambio sin recurrir a un empleo masivo de "bots". En las redes sociodigitales el proceso electoral del 2018 tomó un matiz plebiscitario a favor o en contra de lo que prometía ser una transformación frente a la corrupción, los abusos, las injusticias y las violencias. A lo largo de la campaña, la intensidad del debate y los intercambios en las redes sociodigitales parecían reflejar una sociedad más participativa, activa y decidida a impulsar un cambio.

Una hipótesis probable es que una vez en el gobierno, el presidente López Obrador haya deseado mantener la conversación pública canalizada a través de las redes sociales circunvalando a la gran mayoría de los medios informativos, lo cual al mismo tiempo les restaría capacidad para fijar agenda. Si bien existen dos equipos que oficialmente se encargan de la comunicación digital en la Oficina de la Presidencia de la República, uno encargado del manejo de las redes del Presidente López Obrador (Twitter, FB, Instagram, YouTube del propio presidente) bajo la Dirección General de Comunicación Digital del Presidente, y el otro a cargo de las cuentas del Gobierno Federal (@GobiernoMX, cuentas de Gobierno Federal) bajo la Dirección General de Comunicación y Estrategia Digital, al parecer, desde el final de la campaña se ha mantenido en operación toda una red de apoyos activos, aparentemente sin vinculo oficial con el gobierno, que funcionan todo el tiempo a la vez como una caja de resonancia a favor de las posiciones tanto del presidente como de algunos de sus principales funcionarios, y como enjambre para contrarrestar críticas (Arista, 2020). El semanario Proceso en su edición del 7 de junio de 2020 publicó como reportaje principal una investigación acerca del funcionamiento de esta compleja red (San Martín, 2020). Señala el reportaje que, a diferencia de la administración del presidente Peña Nieto, en la que "se usó una estrategia de automatización en la que cuentas falsas (bots) replicaban mensajes a favor del presidente, en la 4T opera una estructura electoral de apoyo que se trasladó a las redes sociales, conocida como Red AMLO, cuyo objetivo es disciplinar a los críticos del mandatario y crear cercos informativos que acaparan la discusión pública digital" (p.13).

Esta estrategia parece empalmar con la política de comunicación basada también en las conferencias diarias del presidente López Obrador -coloquialmente llamadas "Mañaneras"—en 
las que el primer mandatario, en teoría, no sólo explica las acciones gubernamentales más importantes, sino que, también responde a las preguntas de los medios a través de los periodistas que envían. A primera vista, este ejercicio podría parecer que cumple con dos aspectos de una comunicación gubernamental democrática: informar sobre el ejercicio de gobierno y el rumbo de la política pública, y rendir cuentas. Sin embargo, con frecuencia, el presidente ha utilizado estos espacios para plantear un discurso polarizante que insiste en categorías dicotómicas con fuertes elementos de clase ("pueblo bueno" vs "conservadores") y para definir a grupos, movimientos y personajes específicos como representantes de intereses contrarios a su proyecto. Dentro de estos grupos destacan algunos de los principales medios de comunicación -entre los más nombrados están Reforma, El Financiero, Milenio, El Universal, Grupo Fórmula, The Wall Street Journal, The New York Times y hasta la revista Proceso- a los cuales en diversas ocasiones ha reclamado, desde "no saber hacer periodismo" [sic] hasta ser "cómplices del salinismo neoliberal" [sic].

Si durante los 18 años de la primera alternancia, las relaciones entre muchos de los medios convencionales y los gobernantes en turno se basaron en viejas prácticas clientelares de intercambio, lo que ayuda a explicar en parte la persistencia de las deformaciones del quehacer periodístico informativo - desde la preferencia por la declaración sobre la investigación, hasta no publicar informaciones incómodas para los poderosos, pasando por la pobreza de fuentes y la ausencia de contraste- un paso crucial para quebrar ese modelo ha sido la reducción y la mayor transparencia del gasto en publicidad oficial promovidos por el actual gobierno. No obstante, lo que no queda claro desde una perspectiva de comunicación gubernamental es que hoy se estén construyendo las bases de una relación de "sana distancia" que debería caracterizar el intercambio entre medios y gobiernos en los regímenes democráticos.

En principio, la comunicación gubernamental en una democracia moderna debería orientarse a buscar consensos, a sumar voluntades, a persuadir con datos verificables y con argumentos sólidos basados en perspectivas incluyentes. La comunicación del presidente López Obrador, en cambio, se emplea con frecuencia para descalificar a todos aquellos intereses que no provengan de sus propios proyectos e iniciativas, renunciando a la inclusión, alejando a simpatizantes y aliados iniciales, fracturando la amplia coalición de sectores que lo votó para la presidencia, volviéndose cada vez más partisano y construyendo, en su lugar, enemigos, reales e imaginarios. $Y$ en esta tarea, los grupos afines a su proyecto en las redes sociodigitales parecen cerrar con él y atizan aún más la polarización.

No obstante, la reacción por parte de la mayoría de los medios informativos convencionales tampoco ha sido mejor. En su conjunto, parece que buena parte de estos medios - del mismo modo que la oposición y otros actores económicos y sociales- prefirieran apostar por el retorno de un estatus quo ante, en el que simplemente puedan reconstruir viejas prácticas y relaciones con el Gobierno Federal, antes que aprovechar la coyuntura para transformar de fondo el quehacer periodístico. En este sentido, la práctica informativa de la gran mayoría de los medios convencionales no sólo sigue descansando en la declaración, la nota con pocas fuentes, sin contraste, sin contexto y sin seguimiento, sino que se ha enfocado en resaltar del presidente sus constantes gazapos, sus contradicciones y las anécdotas que suceden durante las giras. Al mismo tiempo, la gran mayoría de las columnas de opinión dedican buena parte de sus espacios a señalar la forma en que las obsesiones presidenciales conducen cada día al país a lo que consideran un abismo insalvable.

A poco menos de la mitad del sexenio, en el debate de la agenda pública parecen estarse perdiendo los terrenos comunes y el diálogo entre las diferentes posiciones. El periodista Jorge Zepeda Patterson define este "ciclo informativo" de la siguiente manera (Zepeda Patterson, 2020),

De siete a nueve de la mañana el presidente hace, con nombre y apellido, el recuento de infamias cometidas en contra de su Gobierno, responde a los ataques y abre nuevos 
frentes [...]. En las siguientes 22 horas, las redes sociales, las columnas políticas y los espacios radiofónicos examinan, extraen consecuencias, ridiculizan y/o distorsionan lo dicho por el presidente. Al día siguiente el ciclo se repite... Durante mucho tiempo creí que en algún momento el presidente rectificaría e invocaría a una verdadera concordia, como lo hizo en su discurso de apertura. Pero cada vez resulta más evidente que él concibe el cambio social a contrapelo de los intereses creados. La intensidad de la resistencia por parte de sus adversarios le confirma que está consiguiendo sus propósitos. Y cuando sus políticas sociales y actos de Gobierno no consiguen generar ese ruido, él se asegura de obtenerlo con la siguiente provocación... Un ciclo interminable.

De este modo, en lo que va de la segunda alternancia es posible decir que, en un contexto político en el que no se ha logrado transitar a un régimen democrático consolidado, el panorama mediático mantiene tanto la diversidad como la independencia condicionada del periodo anterior. Lo que ha cambiado es que ahora el condicionamiento de la independencia ya no parece provenir de su empleo como moneda de intercambio entre los intereses de los medios y los grupos políticos (como en la primera alternancia), sino del juego perverso que se suscita entre la nueva política de comunicación gubernamental (centralizada, austera y agresiva) y el papel partisano, antes que informador, y con las mismas limitaciones de trabajo periodístico de siempre, que han decidido jugar muchas organizaciones informativas convencionales.

\section{Consideraciones finales}

En un régimen en transición los medios, como otros actores de peso, tienen la posibilidad de optar, dentro de ciertos límites estructurales, por determinado tipo de comportamientos en los diferentes momentos de incertidumbre. En México - una democracia no consolidada con formas de acceso al poder abiertas y con formas de ejercicio poco responsables-, estos momentos de incertidumbre han ocurrido tanto durante los procesos de liberalización política, como al inicio de las dos alternancias (2000-2018 y 2018- ). Durante la liberalización y la primera alternancia, una parte importante de los medios informativos convencionales optó por mantener intercambios convenientes con los actores políticos (apoyos económicos diversos por coberturas favorables) en lugar de presionar por la consolidación democrática mediante una transformación más profesional del quehacer informativo, tanto en sus prácticas como en sus funciones. En las prácticas se mantuvieron la nota por sobre cualquier otro género, la declaración de funcionarios y actores políticos, las pocas fuentes, el escaso contraste y la falta de seguimiento ha sido la regla del ecosistema informativo en México. En sus funciones, no pocas veces se distorsionó, sobre todo, el papel de vigilancia (watchdog) a partir de los intereses económicos y políticos de dueños y editores y de sus relaciones con grupos de poder. Resultado: si bien se conformó un panorama mediático aceptablemente diverso, la independencia en un gran número de medios convencionales, quedaba condicionada y limitada.

No obstante, las cosas no parecen haber mejorado a lo largo de la segunda alternancia, en la cual si bien se ha acotado el empleo de la publicidad oficial como elemento clave de los viejos intercambios, no ha logrado sentar las bases de una relación funcional de respeto y distancia con los medios. En el contexto de una democracia que sigue careciendo de mecanismos efectivos de responsabilidad (es decir, una democracia, no consolidada), el sistema mediático mantiene una aceptable diversidad informativa -no sólo por el número de organizaciones, sino al considerar a los nativos digitales, también por su pluralidad ideológica--, al tiempo que no logra consolidar la independencia informativa en gran número de medios convencionales. Las razones tienen que ver tanto con las características de la nueva política de comunicación gubernamental -reducción del gasto en publicidad oficial, centralización de agenda, agresividad contra críticos - como con el papel partisano que muchas organizaciones informativas convencionales han decidido jugar y que mantiene las prácticas tradicionales del quehacer informativo (más enfocado en declaraciones 
que en investigaciones) centradas ahora en exhibir al gobierno más que en promover funciones periodísticas de vigilancia a favor de un debate informado en la sociedad.

\section{Referencias}

Arista, L. (2020, 15 de febrero). Un equipo de nueve personas maneja las 'benditas redes sociales' de AMLO. Expansión. Recuperado de https://politica.expansion.mx/presidencia/2020/02/15/equipo-de-nueve-personas-maneja-lasredes-sociales-de-amlo

Article XIX (2020). Disonancias: Voces en Disputa. Informe anual 2019 de Article XIX. Recuperado de https://articulo19.org/disonancia/

Baracca, S. (2004). Is Mexican Democracy Consolidated? Third World Quarterly, 25 (8), 14691485

Blumler, J. and Gurevitch, M. (2001). 'Americanization' Reconsidered: UK - US Campaign Communication Comparisons Across Time. En L. Bennett. y R. Entman. (Eds.) Mediated Politics. (pp.380-406). Cambridge University Press

Bühlmann, M., Merkel, W., Müller, L. y Wessels, B. (2008). Wie Lässt sich Demokratie am Besten Messen? Politische Vierteljahresschrift, 49(1), 114-122.

Campbell, D., Carayannis, E. y Rehman, S. (2015). Quadruple Helix Structures of Quality of Democracy in Innovation Systems: The USA, OECD countries, and EU member countries in global comparison. Journal of the Knowledge Economy 6(3), 467-493

Carothers, T. (2002). The End of the Transitional Paradigm. Journal of Democracy 13(1), 5-21.

Castillo, T. G. (2015). La reforma constitucional mexicana de 2011 en materia de derechos humanos. Una lectura desde el derecho internacional. Boletín mexicano de derecho comparado, 48(143), 645-696.

Collier, D. y Levitsky, S. (1997). Democracy with Adjectives: Conceptual Innovation in Comparative Research. World Politics, 49(3), 430-451.

Dahl, R. (1971). Polyarchy: Participation and Opposition. Yale University Press.

Diamond, L. y Morlino, L (2004). The Quality of Democracy: An Overview. Journal of Democracy, 15 (4), 20-31.

DOF (2018, 11 de mayo). Decreto por el que se expide la Ley General de Comunicación Social. Diario Oficial de la

Federación.

https://www.dof.gob.mx/nota detalle.php?codigo=5522344\&fecha=11/05/2018

DOF (2019, 29 de enero). Acuerdo por el que se establecen los Lineamientos Generales para el Registro y Autorización de Programas de Comunicación Social y de Promoción y Publicidad de las dependencias y Entidades de la Administración Pública Federal para el Ejercicio Fiscal 2019. Diario Oficial de la https://dof.gob.mx/nota detalle.php?codigo=5556010\&fecha=29/01/2019

DOF (2019, 17 de abril). Acuerdo por el que se establece la Política de Comunicación Social del Gobierno Federal. Diario Oficial de la Federación. https://dof.gob.mx/nota detalle.php?codigo $=5558048 \&$ fecha $=17 / 04 / 2019$

DOF (2020, 23 de abril). Decreto por el que se autoriza a la Secretaría de Hacienda y Crédito Público a recibir de los concesionarios de estaciones de radio y de television el pago del impuesto 
que se indica. Diario Oficial de la Federación. http://dof.gob.mx/nota detalle.php?codigo=5592117\&fecha=23/04/2020

Dunn, J. (1999). Situating Democratic Political Accountability. En A. Przeworski, S. C. Stokes y B. Manin (eds.), Democracy, Accountability and Representation, Cambridge Studies in the Theory of Democracy. Cambridge University Press.

Dussauge, M. (2010). Combate a la corrupción y rendición de cuentas: avances, limitaciones, pendientes y retrocesos. En J.L. Méndez (coord.). Políticas públicas. Pp.207-252. México: El Colegio de México.

FUNDAR (2019). La nueva política de comunicación social es un paso importante pero insuficiente. FUNDAR. Recuperado de https://fundar.org.mx/comunicacion-social-publicidadoficial/

Granados Chapa, M.A. (1981). Examen de la comunicación en México. El Caballito.

Guadarrama, M. (2019). Publicidad oficial, ¿cuánto cuesta desinformar. IMCO. Recuperado de https://imco.org.mx/publicidad-oficial-cuanto-cuesta-des-informar/

Guerrero, M. A. (2010). Los medios de comunicación y el régimen político. S. Loaeza y J. Prud'homme (coords.) Los grandes problemas de México, 14, 231-300.

Guerrero, M.A. (2014). The Liberal Captured Model of Media Systems in Latin America. En M.A. Guerrero y M. Márquez Ramírez (eds.). Media Systems and Communication Policies in Latin America. Palgrave.

Guerrero, M.A. (2019). Democracia y Medios: El papel del periodismo. Cuadernos de Divulgación de la Cultura Democrática, 34, Instituto Nacional Electoral,

Hallin, D.C. y Mancini, P. (2004). Comparing Media Systems. Three Models of Media and Politics. Cambridge University Press

Hobson, C. (2003). Rethinking Democracy: The End of Democratic Transition? Melbourne Journal of Politics, 29, 56-67.

Keane, J. (2013). Democracy and Media Decadence. Cambridge: Cambridge University Press.

Kelley, D., \& Donway, R. (1990). Liberalism and free speech. Democracy and the mass media, 66101.

Levitsky, S y Way, L. A. (2002). The rise of competitive authoritarianism. Journal of Democracy, 13 (2), 51-65.

Loaeza, S. (1987). El Partido Acción Nacional: de la oposición leal a la impaciencia electoral. La vida política mexicana en la crisis, 77-106.

Mazzuca, S.L. (2010), Access to Power VS Exercise of Power: Reconceptualizing the Quality of Democracy in Latin America. Studies in Comparative International Development.45 (3), 334-357.

Merino, M. (1999). Corrupción y servicio profesional en México: una mirada desde la cultura política". Bien Común y Gobierno, 5 (56).

Møller, J. y Skanning, S.E. (2010). Beyond the Radial Delusion: Conceptualizing and Measuring Democracy and Non-Democracy. International Political Science Review, 31 (3), 261-283.

Møller, J. y Skaaning, S.E. (2012). Systematizing Thin and Thick Conceptions of the Rule of Law. Justice System Journal 33(2), 136-153

Munck, G. L. (2016). What is Democracy? A reconceptualization of the quality of democracy. Democratization 23(1), 1-26. 
Negrine, R. y Papathanassopoulos, S. (2005). The 'Americanization' of Political Communication: A Critique. En R. Negrine. y J. Stanyer (Eds.). The Political Communication Reader. (pp.102-106). Routledge.

Norris, P. (2012). Making Democratic Governance Work: How Regimes Shape Prosperity, Welfare, and Peace. Cambridge University Press.

O'Donnell, G. (1998). Horizontal Accountability and New Polyarchies. [Working Paper 253]. Helen Kellogg Institute for International Studies, University of Notre Dame.

O'Donnell, G. (1999). Polyarchies and the (Un)Rule of Law in Latin America. En J. Mendez, G. O'Donnell y P.S. Pinheiro (eds.). The Rule of Law and the Underprivileged in Latin America. Notre Dame Press.

O'Donnell, G. y Schmitter, P. (1986). Transitions from Authoritarian Rule. V.4 Tentative Conclusions about Uncertain Democracies. Johns Hopkins University Press.

Pardo, M.C. (2009). Los mecanismos de rendición de cuentas en el ámbio ejecutivo de gobierno. En: www.rendiciondecuentas.cide.edu

Panagopoulos, E.P. (1986). Essays on the History and Meaning of the Checks and Balances. University Press of America.

Pickel, S., Breustedt, W. y Smolka, T. (2016). Measuring the quality of democracy: Why include the citizens' perspective? International Political Science Review, 37(5), 645-655.

Plasser, F. (2002). Global political campaigning: a worldwide analysis of campaign professionals and their practices. Praeger.

Redacción AN (2012, 18 de mayo). El estudiante que cuestionó, ‘¿cuál es el candidato de Televisa? Aristegui Noticias. Recuperado de https://aristeguinoticias.com/1806/mexico/elestudiante-que-cuestiono-cual-es-el-candidato-del-televisa/

San Martín, N. (2020, 07 de junio). El 'ejército' presidencial en Twitter, de los 'bots' a una red de carne y hueso. Proceso, 2275, pp.12-16.

Schmitter, P. C. y Karl, T. L. (1996). What Democracy Is...and Is Not. En L. Diamond y M. Plattner, (eds.). The Global Resurgence of Democracy. Johns Hopkins University Press.

SESNSP (2020). Reportes de Víctimas por Año. Recuperado de https://www.gob.mx/sesnsp/acciones-y-programas/victimas-nueva-metodologia?state=published

Siebert, F., Peterson, T. y Schramm, W. (1956). Four Theories of the Press. The Authoritarian, Libertarian, Social Responsibility and Soviet Communist Concepts of What the Press Should Be and Do. Books for Libraries Press.

Smith, P. y Ziegler, M. (2008). Lilberal and Illiberal Democracy in Latin America. Latin American Politics and Society, 50(1), 31-57.

Vaca, M. (2017). Four Theories of the Press: 60 years and counting. Londres: Routledge.

Villalpando, A. y Morales, C. (2020, 03 de agosto). Recortes presupuestales: los costos del ahorro. Este País. Recuperado de: https://estepais.com/home-slider/recortes-presupuestales-loscostos-del-ahorro/

Voltmer, K. (2013). The Media in Transitional Democracies. Polity Press.

WJP (2020). Índice de Estado de Derecho 2019-2020. Hallazgos. Washington, D.C.: WJP. Recuperado de https://worldjusticeproject.mx/wp-content/uploads/2020/04/mx-insights-full-2.pdf 
Zepeda Patterson, J. (2020, 17 de junio). López Obrador como catarsis o ¿por qué se pelea el presidente? El País. Recuperado de https://elpais.com/opinion/2020-06-17/lopez-obrador-comocatarsis-o-por-que-se-pelea-el-presidente.html

\section{NOTAS}

'Esta perspectiva inicia con la obra de Siebert, Peterson y Schramm (1956) que marcó la forma de entender los sistemas mediáticos como variable dependiente de los sistemas políticos. Hallin y Mancini (2004) toman distancia de una concepción tan estática al partir, no de establecer casos con base en modelos teóricos preconcebidos, sino de estudiar casos empíricos con el fin de hallar semejanzas y particularidades. Su trabajo, sin embargo, se limita al estudio de aquellos sistemas políticos que, de antemano, pueden definirse como democracias relativamente consolidadas, lo que deja fuera a los regímenes en transición.

ii Se aclara que una "alternancia" no significa una "transición", ni un cambio de régimen. Significa aquí un cambio en el partido y grupo gobernante en el poder a nivel federal, para el caso de México, sin que necesariamente cambien las reglas del ejercicio del poder.

iii Los atributos son: libertad para asociarse y formar organizaciones; libertad de expresión; derecho al voto; derecho de líderes políticos de competir por apoyo; fuentes de información diversas y alternativas (con estas cinco garantías, los ciudadanos -considerados políticamente iguales-tienen la posibilidad de formular sus preferencias políticas); posibilidad de que, en principio, cualquier ciudadano pueda ser electo a un cargo público; elecciones libres y abiertas (con las siete garantías anteriores los ciudadanos tienen posibilidad de manifestar sus preferencias de manera individual o colectiva frente a los demás ciudadanos y al gobierno); y, finalmente, debe haber instituciones que aseguren que las políticas públicas sean, en cierta medida, el reflejo de las preferencias electorales. Ver Robert Dahl, Polyarchy: Participation and Opposition, New Haven, Yale University Press, 1971.

${ }^{\text {iv }}$ Para un análisis amplio sobre el concepto de calidad de la democracia, véase Munck (2016).

$\checkmark$ Para un análisis detallado de las dos dimensiones - acesso y ejercicio del poder-en democracias, véase Guerrero, M.A. (2004). México: la paradoja de su democracia, México, Universidad Iberoamericana.

vi Como parte de un proceso de transición política desde los autoritarismos, se inician procesos de liberalización que pueden, o no, conducir a otros de amplia democratización. Liberalizar un régimen implica cambios importantes, como mayor apertura, reconocimiento y extensión de derechos, así como más participación autónoma de la sociedad, y supone sobre todo un cambio en el comportamiento y la conducta del régimen y no una reestructuración institucional, pues las reglas fundamentales -formales e informalesno cambian (O'Donnell y Schmitter, 1986). En México este proceso inicia con la reforma electoral de 1977 y hasta 1996, cuando se abre la arena electoral y se comienzan a garantizar derechos de participación. Sin embargo, el tránsito hacia una consolidación democrática requiere cambios en la estructura de la autoridad que hagan más responsable el ejercicio del poder.

vii Se debe señalar que, al menos entre las décadas de 1980 y 1990, gran parte de la oposición política y de la literatura en México puso el énfasis en lo electoral como la llave que abriría el sistema político a la democracia -también entendida, limitadamente, en sus términos procedimentales, es decir limitada a procesos de competencia por el voto competitivos y abiertos.

viii Este periodo de 18 años se define aquí como primera alternancia, pues los tres gobiernos que la componen comparten dos características básicas. Por una parte, una misma visión del modelo de desarrollo basado en la apertura, competitividad, exportación y en un papel reducido de lo público frente a lo privado. Y, por la otra, una falta de voluntad política para que, más allá de reformas y de organismos autónomos, se vuelvan realmente efectivas las medidas y acciones tendientes hacia un ejercicio del poder más responsable.

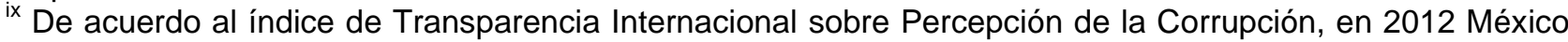
ocupaba el lugar 105 de los 180 países que se medían, mientras que para 2018, se cayó al sitio 138. Se puede consultar en: https://www.transparency.org/en/cpi\#

${ }^{x}$ El propio Presidente Peña se vio involucrado en un escándalo de tráfico de influencias en lo que mediáticamente se llamó "la Casa Blanca de Peña Nieto". El reportaje, que llevó a cabo el equipo de la periodista Carmen Aristegui, apareció el 9 de noviembre de 2014. Se puede consultar en: https://aristeguinoticias.com/0911/mexico/la-casa-blanca-de-enrique-pena-nieto/ 
xi De acuerdo con datos del Secretariado Ejecutivo del Sistema Nacional de Seguridad Pública, 2019 ha sido el año más violento el que se tenga registro con 34,608 asesinatos dolosos. Además, comparando enero a mayo de 2018 -último año del gobierno del Presidente Peña Nieto-con el mismo periodo de 2020, hay también un incremento de 13,515 a 14,631 homicidios dolosos. Ver: SESNSP, Reportes de Víctimas por Año, disponible en: https://www.gob.mx/sesnsp/acciones-y-programas/victimas-nuevametodologia?state=published

xii Ver reporte completo: WJP (2020). Índice de Estado de Derecho 2019-2020. Hallazgos. Washington: WJP. Disponible en: https://worldjusticeproject.mx/wp-content/uploads/2020/04/mx-insights-full-2.pdf

xiii En la gran mayoría de los casos esta apertura radiofónica no obedecía a una vocación democratizadora de los dueños, sino a una necesidad de hacer sus estaciones más atractivas ante la competencia de la banda FM, el crecimiento en el número de concesiones de radio que se otorgó durante el sexenio del Presidente De la Madrid (1982-1988) y la disminución del pastel publicitario ante la crisis económica. Este proceso se ha analizado con detalle en otro trabajo. Véase: Guerrero, M.A. (2009). The Emergence of Political Pluralism in Mexican Broadcasting, Saarbrücken, Alemania, VDM Verlag.

${ }^{x i v}$ Es necesario apuntar que ese año Televisa había estado perdiendo audiencia frente a las telenovelas de TV Azteca y frente a su proyecto noticioso, "Fuerza Informativa Azteca", conducido por Javier Alatorre.

$x v$ Un ejemplo de estas alianzas mediáticas con determinados grupos y actores políticos eran las llamadas "tarifas políticas" que los medios cobraban de forma diferenciada, de acuerdo al partido y candidato, por insertar propaganda en los mismos espacios y tiempos en una contienda. Otro ejemplo era la venta de paquetes mediáticos a candidatos y gobernantes que incluían desde coberturas favorables hasta entrevistas a modo.

${ }^{x v i}$ Resulta interesante que estas alianzas tácticas no solo se daban a partir del gasto publicitario explícito en forma de promoción y campañas gubernamentales, sino también de "paquetes publicitarios" que los medios -y algunos comunicadores en sus espacios informativos de radio y TV-- ofrecían a los más altos funcionarios en los diferentes gobiernos, los cuales incluían entrevistas normalmente a modo e inserción de "infomerciales" pagados como si fueran notas informativas.

xvii Los "tiempos fiscales" para la radiodifusión fueron una medida implementada por el gobierno de Gustavo Díaz Ordaz en 1969 para que los medios de comunicación pagarán impuestos equivalentes a un gravamen de $25 \%$ de los ingresos facturados de las empresas concesionarias. La alternativa al pago de este impuesto era hacerlo "en especie" mediante la cesión al gobierno de $12.5 \%$ de tiempo diario de transmisión que, en principio, se utilizaría para campañas públicas. En realidad, el gobierno nunca tuvo la capacidad de producir tal cantidad de contenidos como para ocupar ese tiempo, que no era acumulable y que al final de cuentas funcionaba como espacio de negociación e intercambio también. En el gobierno del Presidente Vicente Fox (2000-2006) este acuerdo se modificó y los "tiempos fiscales" en favor del gobierno se redujeron a sólo 18 minutos diarios de transmisión en televisión y 35 minutos en radio. Ahora, con este nuevo Decreto del Presidente López Obrador, los "tiempos fiscales" quedan en 11 minutos para la TV y 21 minutos para la radio (DOF 23/04/2020). 